\title{
An exploration study to detect important factors influencing on compulsive buy: A case study of Shahrvand chain stores
}

\author{
Ali Alikhani ${ }^{a}$, Jamshid Salehi Sadaghiani ${ }^{\mathrm{b}}$, Maryam Jabbarzadeh ${ }^{\mathrm{a}^{*}}$ and Mehdi Asgarielo ${ }^{\mathrm{a}}$
}

${ }^{a}$ Department of Business Management, North Branch, Islamic Azad University, Tehran, Iran

${ }^{b}$ Department of Management, Allameh TabaTabayi University Tehran, Iran

\section{H R O N I C L E}

Article history:

Received January 30, 2013

Received in revised format

20 May 2013

Accepted May 282013

Available online

May 292013

Keywords:

Consumer behavior

Food industry

Emotional Instability

Attractive Appearance

\section{A B S T R A C T}

Consumer behavior plays an important role on purchasing goods and services from food chain stores. In this paper, we present a study to detect important factors impacting consumer behavior on Iranian food industry, named Shahrvand. The proposed study selects 384 customers who made some purchases during the year of 2012. Structural equation modeling has been performed to detect important factors influencing compulsive buying including emotional instability, attractive appearance, social recognition, financial success. Cronbach alphas have been calculated for these four mentioned items were well above 0.80 , which validated the overall questionnaire of the survey. The results of our survey have confirmed that all four independent variable influenced positively on compulsive buy, significantly.

(C) 2013 Growing Science Ltd. All rights reserved.

\section{Introduction}

Coley and Burgess (2003) compared men and women for differences in influential and cognitive processes related to impulse buying behavior. They also detected gender differences in terms of impulsive purchases made from different product categories. They detected significance difference between men and women in the frequency with different types of products such as shirts/sweaters, pants/skirts, coats, underwear/lingerie, etc. (Workman, 2010). Constantinides (2004) addressed one of the fundamental issues of e-marketing, which is how to absorb and win over the consumer in the highly competitive Internet marketplace. Their investigation examined how e-marketers could impact the outcome of the virtual interaction and buying process by concentrating their marketing attempts on elements shaping the customer's virtual experience, the Web experience.

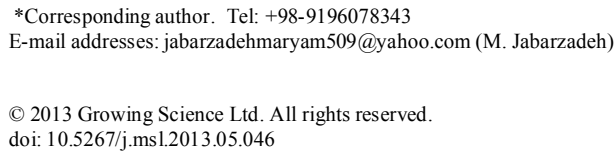


According to Faber and O'guinn (1992) advancements in understanding problematic behaviors need the capability to detect affected or at-risk individuals and they reported the development of a scale to detect compulsive buyers. Faber and O'Guinn (1988) presented some evidence of a kind of consumption, which could be called "compulsive" and demonstrated that this kind of consumption was associated with some sort of certain characteristics of materialism, but not possessiveness. They recommended that the actual consumption experience could possess aspects akin to those observed in other abusive behaviors, but could be essentially unrelated to desires for material objects for their intrinsic qualities.

Johnson and Attmann (2009) investigated compulsive consumption within a product specific context using a hierarchical model adapted from Mowen and Spears. They used path analysis and reported significant relationships between neuroticism and materialism, neuroticism and compulsive clothing buying, materialism and fashion interest, and fashion interest and compulsive clothing buying. According to Kellett and Bolton (2009), compulsive buying (CB) has become a topic of interesting area of research and this hiatus means that there is currently little theoretical guidance for clinicians endeavors to intervene with $\mathrm{CB}$ clients and no established model for researchers to evaluate, distil and refine.

Lee and Mysyk (2004) studied critically the labeling of compulsive buying in terms of medicalization from the perspective of both medical and non-medical social control of "deviant" consumers. Miltenberger et al. (2003) investigated direct and retrospective assessment of factors contributing to CB. Mueller et al. (2010) estimated prevalence of CB in Germany and its association with socio demographic characteristics and depressive symptoms.

Phau and Woo (2008) investigated money attitudes and credit card usage, between compulsive and non-compulsive buyers, of young Australians and reported that $\mathrm{CB}$ were more likely to perceive money as a source of power and prestige. Roberts and Jones (2001) performed an investigation on money attitudes, credit card use, and compulsive buying among American college students. They reported that the money attitudes power prestige, distrust, and anxiety were closely associated with $\mathrm{CB}$ and that credit card use often moderates these relationships. Roberts and Pirog III (2004) performed an investigation on personal goals and their role in consumer behavior. Shahjehan et al. (2012) investigated the effect of personality (Big Five Personality Traits) on buying behavior (impulsive and compulsive buying).

\section{The proposed study}

In this paper, we present a study to detect important factors impacting consumer behavior on Iranian food industry, named Shahrvand. The proposed study uses the following framework to examine different hypotheses,

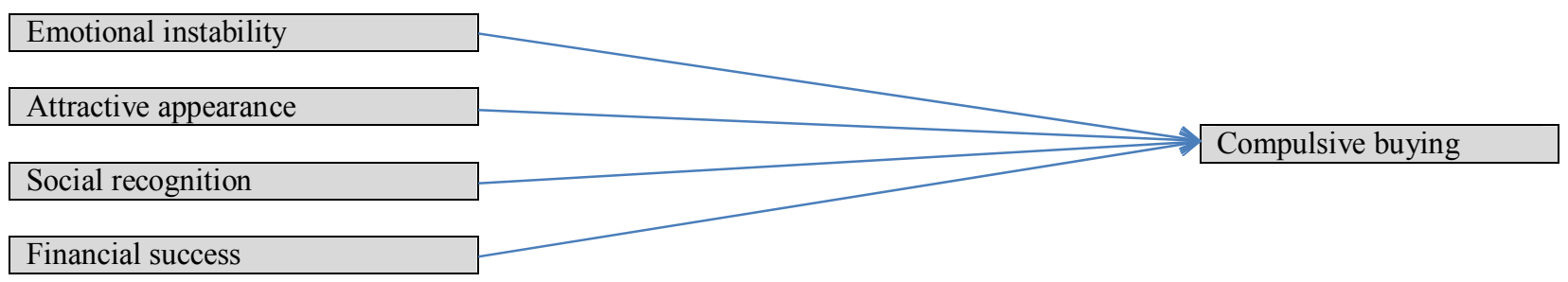

Fig. 1. The proposed study

As we can observe from Fig. 1, the proposed study of this paper considers the effects of four variables on compulsive buying (CB). The sample size is calculated as follows,

$$
N=Z_{\alpha / 2}^{2} \frac{p \times q}{e^{2}},
$$


where $N$ is the sample size, $p=1-q$ represents the probability, $z_{\alpha / 2}$ is CDF of normal distribution and finally $\varepsilon$ is the error term. For our study we assume $p=0.5, z_{\alpha / 2}=1.96$ and $e=0.99$, the number of sample size is calculated as $N=384$. The proposed study selects 384 customers who made some purchases during the year of 2012. Structural equation modeling has been performed to detect important factors influencing compulsive purchasing including emotional instability (EI), attractive appearance (AA), social recognition (SR), financial success (FS). There are four hypotheses associated with the proposed study of this paper as follows,

1. Emotional instability positively influences on compulsive buying.

2. Attractive appearance positively influences on compulsive buying.

3. Social recognition positively influences on compulsive buying.

4. Financial success positively influences on compulsive buying.

Cronbach alphas have been calculated for these four mentioned items were well above 0.80, which validated the overall questionnaire of the survey. Table shows details of Cronbach alpha in preliminary and final stages.

Table 1

The summary of Cronbach alpha in preliminary and final stages

\begin{tabular}{lccc}
\hline Variable & \# of questions & Preliminary stage & Final stage \\
\hline Financial success & 4 & 0.792 & 0.845 \\
Social recognition & 4 & 0.842 & 0.728 \\
Emotional instability & 5 & 0.813 & 0.843 \\
Attractive appearance & 6 & 0.924 & 0.933 \\
Compulsive buying & 8 & 0.856 & 0.855 \\
\hline
\end{tabular}

The proposed study of this paper uses structural equation modeling to verify different hypotheses of this survey.

\section{The results}

In this section, we present details of our findings on testing four hypotheses of this paper. Fig. 2 shows details of the results of structural equation modeling.
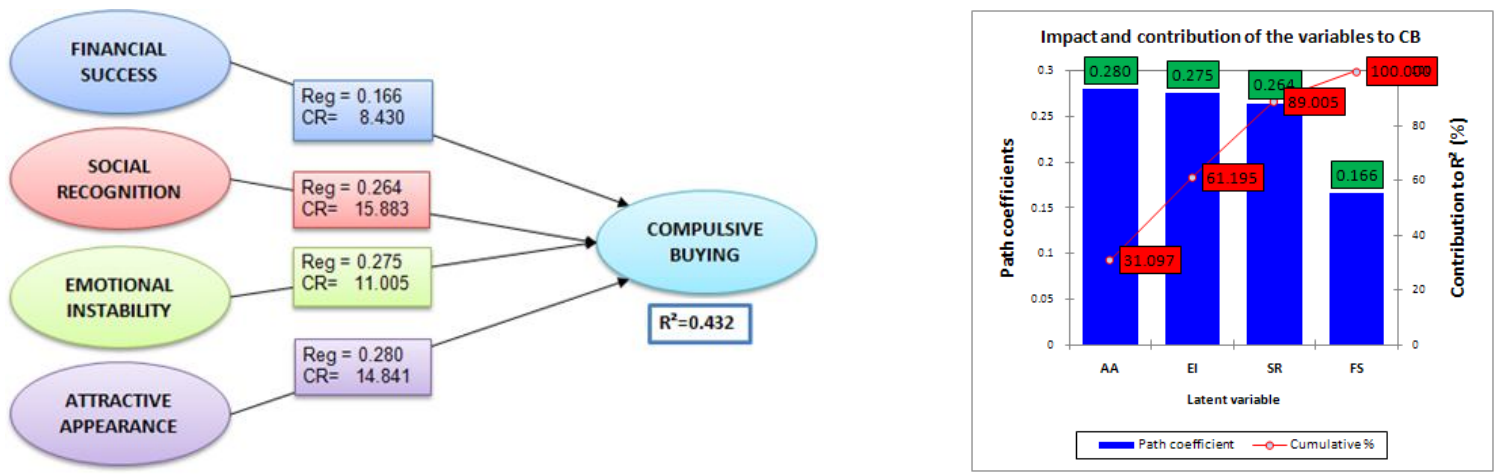

Fig. 2. The results of structural equation modeling as well as standard coefficients

As we can observe from the results of Fig. 2, all four components have positive impacts on compulsive buying when the level of significance is five percent. Table 2 shows details of our results. The results of Table 2 confirm that all coefficients are statistically significance with $\alpha=5 \%$. 
Table 2

The summary of SEM implementation

\begin{tabular}{|c|c|c|c|c|c|c|c|}
\hline \multirow[b]{2}{*}{ Independent variable } & \multirow[b]{2}{*}{ Dependent variable } & \multicolumn{3}{|c|}{ Test } & \multicolumn{3}{|c|}{ Coefficients } \\
\hline & & $\begin{array}{c}\text { Standard } \\
\text { coefficient }\end{array}$ & $\begin{array}{c}\text { Estimated } \\
\text { error }\end{array}$ & $\begin{array}{c}\text { Critical } \\
\text { value }\end{array}$ & $\begin{array}{c}\text { Total } \\
\text { coefficient }\end{array}$ & $\begin{array}{c}\text { Each } \\
\text { component }\end{array}$ & $\%$ \\
\hline Financial success & Compulsive buy & 0.166 & 0.02 & 8.43 & 0.432 & 0.048 & 10.995 \\
\hline Social recognition & Compulsive buy & 0.264 & 0.017 & 15.883 & & 0.12 & 27.81 \\
\hline Emotional instability & Compulsive buy & 0.275 & 0.025 & 11.005 & & 0.13 & 30.098 \\
\hline Attractive appearance & Compulsive buy & 0.28 & 0.019 & 14.841 & & 0.134 & 31.097 \\
\hline Equation & $\mathrm{CB}=0.1662039264$ & 0.264333 & $\mathrm{R}+0.274$ & $97 * \mathrm{EI}$ & $5182211^{*}$ & & \\
\hline
\end{tabular}

\section{Discussion and conclusion}

In this paper, we have presented an empirical investigation to study the effects of different factors on compulsive buying in one of Iranian chain stores named Shahrvand located in city of Tehran, Iran. The proposed study designed a questionnaire and examined the impacts of financial success, social recognition, emotional instability as well as attractive appearance on compulsive buy based on the implementation of structural equation modeling. The results of our survey have confirmed that all four independent variables influenced positively on compulsive buy, significantly.

\section{References}

Coley, A., \& Burgess, B. (2003). Gender differences in cognitive and affective impulse buying. Journal of Fashion Marketing and Management, 7(3), 282-295.

Constantinides, E. (2004). Influencing the online consumer's behavior: the web experience. Internet research, 14(2), 111-126.

Faber, R. J., \& O'Guinn, T. C. (1988). Compulsive consumption and credit abuse. Journal of Consumer Policy, 11(1), 97-109.

Faber, R. J., \& O'guinn, T. C. (1992). A clinical screener for compulsive buying. Journal of consumer Research, 459-469.

Johnson, T., \& Attmann, J. (2009). Compulsive buying in a product specific context: clothing. Journal of Fashion Marketing and Management, 13(3), 394-405.

Kellett, S., \& Bolton, J. V. (2009). Compulsive buying: A cognitive-behavioural model. Clinical psychology \& psychotherapy, 16(2), 83-99.

Lee, S., \& Mysyk, A. (2004). The medicalization of compulsive buying. Social science \& medicine, 58(9), 1709-1718.

Miltenberger, R. G., Redlin, J., Crosby, R., Stickney, M., Mitchell, J., Wonderlich, S., ... \& Smyth, J. (2003). Direct and retrospective assessment of factors contributing to compulsive buying. Journal of Behavior Therapy and Experimental Psychiatry, 34(1), 1.

Mueller, A., Mitchell, J. E., Crosby, R. D., Gefeller, O., Faber, R. J., Martin, A., ... \& de Zwaan, M. (2010). Estimated prevalence of compulsive buying in Germany and its association with sociodemographic characteristics and depressive symptoms. Psychiatry research, 180(2), 137-142.

Phau, I., \& Woo, C. (2008). Understanding compulsive buying tendencies among young Australians: the roles of money attitude and credit card usage. Marketing Intelligence \& Planning, 26(5), 441458.

Roberts, J. A., \& Jones, E. (2001). Money attitudes, credit card use, and compulsive buying among American college students. Journal of Consumer Affairs, 35(2), 213-240.

Roberts, J. A., \& Pirog III, S. F. (2004). Personal goals and their role in consumer behavior: the case of compulsive buying. Journal of Marketing Theory and Practice, 61-73.

Shahjehan, A., Qureshi, J. A., Zeb, F., \& Saifullah, K. (2012). The effect of personality on impulsive and compulsive buying behaviors. African Journal of Business Management, 6(6), 2187-2194.

Workman, L. (2010). The Essential Structure of Compulsive Buying: A Phenomenological Inquiry. 